\title{
Психомогия безопасности
}

\section{УДК 159.9.072}

\section{Специфика восприятия некоторых аспектов образовательной среды обучающимися группы риска}

\section{The specifics of the perception of some aspects in the educational environment by students of the risk group}

Ничипоренко Н.П., ФГБНУ «Институт педагогики, психологии и социальных проблем», nichiporenko.n@yandex.ru

Nichiporenko N., Institute of Pedagogy, Psychology and Social Problems,
nichiporenko.n@yandex.ru

DOI: $10.51379 / \mathrm{KPJ} .2021 .149 .5 .037$

Статья выполнена по государственному заданию № 0599-2019-0043 «Проблема отклоняющегося поведения в системе современного человековедения».

Ключевые слова: образовательная среда, психологическая безопасность, психологические риски, социально-психологический климат, психологическое здоровье икольников и студентов, отклоняющееся поведение, негативные психические состояния, агрессивность, депрессивность.

Keywords: educational environment, psychological safety, psychological risks, social and psychological climate, psychological health students, deviant behavior, negative mental state, aggression, depression.

Аннотация. Данная статья посвящена проблеме отношений между субъектами образовательной среды в контексте психологической безопасности. Актуальность темы обусловлена необходимостью своевременной профилактики отклоняющегося поведения среди обучающихся, наиболее уязвимых в отношении негативных влияний со стороны сочиальных факторов. Цель статьи - выявить общие и специфические черты восприятия отдельных аспектов образовательной среды обучающимися группь риска. Мониторинг охватывал 244143 обучающихся школ 6-11 классов, колледжей и вузов РТ. В группу риска вошли 860 человек, имеющие высокий суммарный показатель агрессивности и депрессивности. Анализ результатов исследования выявил следующие закономерности: обучаюшиеся группы риска достоверно чаще своих сверстников испытывают негативные эмоциональные состояния, связанные с учебой, подвергаются буллингу в образовательной среде, сталкиваются с проявлениями насилия на улище, описывают как небезопасные отношения со сверстниками и учителями. Результаты проведенного исследования могут быть применимы в нескольких направлениях: психологическое просвещение всех субъектов образовательного процесса, профилактика психических расстройств агрессивно-депрессивного спектра, психогигиена образовательной среды, психологическое сопровождение обучающихся группь риска и превенщия отклоняющегося поведения антисоциальной направленности. Данное исследование предназначено для специалистов, способных повлиять на улучшение образовательного пространства учебных заведений: психологов, педагогов, представителей администрации, сотрудников правоохранительных органов, причастных к работе с детьми и молодежью.

Abstract. This article is devoted to the problem of relations between the subjects of the educational environment in the context of psychological security. The relevance of the topic is due to the need for timely prevention of deviant behavior among students who are most vulnerable to negative influences from social factors. The purpose of the article is to identify general and specific features of the perception of certain aspects of the educational environment by students of the risk group. The monitoring covered 244,143 students of schools (grades 6 - 11), colleges and universities of the Republic of Tatarstan. The risk group included 860 people with a high total index of aggressiveness and depression. The analysis of the results of the study revealed the following patterns: students at risk are significantly more likely than their peers to experience negative emotional states associated with studying, are bullied in the educational environment, face violence on the street. They describe their relationships with peers and teachers as 
unsafe. The results of the conducted research can be applied in several directions: psychological education of all subjects of the educational process, prevention of mental disorders of the aggressive-depressive spectrum, psychohygiena of the educational environment, psychological support of students at risk and prevention of deviant behavior of an antisocial orientation. This study is intended for specialists who can influence the improvement of the educational space of educational institutions: psychologists, teachers, representatives of the administration, law enforcement officers involved in working with children and youth.

Введение. В данной статье проблема отклоняющегося поведения рассмотрена в связи с различными характеристиками образовательного пространства. Исследование выполнено на стыке психологии личности, клинической психологии, педагогической и социальной психологии, и представляет собой психолого-педагогический анализ различных характеристик образовательной среды и некоторых социальных факторов, имеющих прямое отношение к вопросам безопасности.

Актуальность темы обусловлена необходимостью своевременной профилактики отклоняющегося поведения среди обучающихся, наиболее уязвимых в отношении негативных социальных влияний. В силу гетерогенности детско-подростково-юношеской когорты прогноз антисоциального поведения представляет собой сложнейшую задачу, решение которой требует понимания закономерностей взаимодействия множества переменных - индивидуальнопсихологических, макро- и микро-социальных факторов среды, условий конкретной ситуации и их преломления в индивидуальном сознании.

Цель настоящего исследования - анализ особенностей восприятия некоторых аспектов образовательной среды обучающимися группы риска. Задачи исследования: выделить и описать группу риска обучающихся на основе субъективных маркеров психологического здоровья, представленных агрессивностью и депрессивностью; провести сравнительный качественный анализ восприятия некоторых параметров образовательной среды, значимых с точки зрения психологической безопасности личности, в общей выборке и в группе риска; выявить общие и специфичные характеристики восприятия образовательной среды в общей выборке и в группе риска.

Методологическую основу исследования составили следующие положения и концепции. 1. Подход отечественных психологов к описанию феномена безопасности через категории деятельности, сознания и отношений субъекта с миром [7]. 2. Концепция отношений В.Н. Мясищева, объясняющая этиопатогенетические механизмы психической адаптации в норме и при еe нарушениях [11]. Базовый конструкт данной концепции - субъект отношений, личность как система и многообразие отношений человека к окружающей действительности [8]. В определении В.Н. Мясищева «Психологические отношения человека в развитом виде представляют целостную систему индивидуальных, избирательных, сознательных связей личности с различными сторонами объективной действительности. Эта система вытекает из всей истории развития человека, она выражает его личный опыт и внутренне определяет его действия, его переживания» [12, c.7]. 3. Закономерности формирования отклонений в подростково-юношеском возрасте, изложенные в фундаментальной работе А.Е. Личко [10]. 5. Концепция психологической безопасности образовательной среды И.А. Баевой [2] и ее дальнейшие разработки [1;3;4]. 4. Концепция социального остракизма Williams K.D., согласно которой групповые действия игнорирования, отвержения, исключения, и в своем крайнем проявлении - буллинга, являются источником тяжелой депривации базовых потребностей человека в принадлежности, самоуважении, контроле, безопасности, причиняя «социальную боль» [16].

Основные исследования российских авторов в области психологической безопасности сконцентрированы в области безопасности школы [1;2], колледжей [4] и немного затрагивают систему высшего образования [5;14]. В качестве основных компонентов психологической безопасности образовательного пространства выступают отношение к образовательной среде, удовлетворенность ее основными характеристиками и защищенность от психологического насилия [2-4]. В зарубежных исследованиях обосновано влияние образовательной среды на мотивацию и самооценку обучающихся, степень адаптации к образовательной среде, устойчивое позитивное психологическое состояние обучающихся. Также показано влияние на уровень адаптации различных стресс-факторов - учебной нагрузки, проблем в учебе, отношений с родителями, семейных конфликтов, межличностной агрессии, социального климата [9].

Конструктами, близкими к предмету нашего исследования, являются понятия социальнопсихологического климата и школьного климата, 
изучаемые в дискурсе безопасности. Исследование, проведенное Е.В. Эгамбердиевой, доказывает наличие достоверных взаимосвязей между компонентами психологического климата (эмоционального, когнитивного и поведенческого), удовлетворенностью характеристиками образовательной среды и оценками психологической безопасности образовательной среды студентами вуза [14].

Школьный климат, понятие которого анализируется в статье Н.Ю. Федуниной, отражает качественную сторону школьной жизни, включает структурную, культурную и индивидуальную составляющие и состоит из множества компонентов: нормы и ценности, традиции, правила, санкции, фон взаимоотношений, забота о нуждах учащихся, и многие другие социально-психологические параметры. На индивидуальном уровне располагаются субъективные оценки школьного климата разными участниками образовательного процесса. «Понятие школьного климата во многом покоится на впечатлении, субъективном восприятии, на невидимом. Введение феноменологического фактора в определение данного понятия делает его зависимым от восприятия участника процесса» $[13$, с.118]. В этом ракурсе важно исследовать именно субъективные представления обучающихся о различных аспектах образовательной среды.

В качестве маркера психологического здоровья и благополучия личности в нашем исследовании фигурируют два параметра: уровень депрессивности и уровень агрессивности. Взаимосвязи депрессивности и образовательной среды описаны в исследовании Briere F.N. [15]: подростки, посещающие среднюю школу с лучшей социально-образовательной средой, имеют меньший риск развития депрессивных симптомов, что говорит о важности изучения образовательной среды и ее протекционного потенциала.

Агрессивность в контексте социального остракизма подробно рассмотрена в обзорной статье Е.Э. Бойкиной. Здесь, на основе анализа ряда зарубежных исследований показано, что социальный остракизм выступает фактором среды, опосредующим агрессивные реакции, в том числе радикальной направленности [6]. Таким образом, малозаметные внешне формы социального остракизма (игнорирование, исключение, отвержение) и его более организованные проявления в виде буллинга и моббинга являются мощным триггером агрессии.

Материаль и методы исследования. На базе ресурсного центра координации деятельности психологических служб Республики Татарстан «Ориентир» в 2020г. был проведен сплошной мониторинг образовательной среды. Использование данных мониторинга не ограничено грифом «ДСП» и согласовано с кураторами проекта по линии АТК и Совета Безопасности РТ. Автор статьи является сотрудником ресурсного центра «Ориентир» (методист, супервизор); выбор стратегии анализа данных, вторичная статистическая обработка результатов мониторинга и представленный в статье текст полностью выполнены Ничипоренко Н.П.

В исследовании принимали участие 244143 респондента: учащиеся школ 6-11 классов, студенты средних специальных и высших учебных заведений различных регионов Республики Татарстан; из них 52,7\% юношей и 47,2\% девушек. Возраст опрошенных - от 12 до 23 лет.

В рамках мониторинга был проведен анкетный опрос обучающихся и скрининговое психодиагностическое обследование. В данной статье анализируются 27 вопросов анкеты, касающихся различных сторон образовательной среды, в том числе пункты, имеющие непосредственное отношение к психологической безопасности обучающихся. В качестве маркеров психологического здоровья респондентов выступали уровень депрессивности и уровень агрессивности, представленные сырыми тестовыми баллами и нормализованными значениями. Для диагностики депрессивности использовалась шкала оценки депрессии В. Зунга (в адаптации Т.И. Балашовой) - опросник, разработанный для дифференциальной диагностики депрессивных проявлений и состояний, близких к депрессии; данный тест эффективен для скрининг-диагностики при массовых исследованиях и в целях предварительного доврачебного обследования. Агрессивность измерялась при помощи опросника А. Басса и М. Перри (BPAQ-24, в адаптации Ениколопова С.Н., Цибульского Н.П.), диагностирующего склонность к агрессии (общий показатель) и три ее составляющие: физическая агрессия, гнев, враждебность.

В ходе обработки данных были нормализованы сырые баллы по параметрам агрессивности и депрессивности, затем подсчитывались процентные показатели положительных ответов на вопросы анкеты (ответили «да» или «скорее да») в двух группах общей выборке (244143 чел.) и в группе риска (860 чел.). Статистическая обработка результатов исследования проводилась с использованием 
метода сравнений (угловое преобразование Фишера).

Группа риска составила $0,35 \%$ от числа всех опрошенных и была образована респондентами, получившими высокий суммарный показатель нормализованных баллов агрессивности и депрессивности (более 7,1 балла). Гендерный состав группы риска - 551 чел. (64\%) мужского пола и 309 чел. (36\%) женского пола.

Результатьл исследования. Сгруппировав вопросы анкеты по содержанию, мы получили несколько категорий, характеризующих различные параметры образовательной среды. В их числе - общий эмоциональный фон пребывания в учебном заведении (вопросы 1, 2, 7 ,
10); экологичность расписания (вопрос 3); свобода в обращении с образовательной средой (вопросы 5, 6); безопасность и защищенность от необоснованной критики педагогов (вопросы 8, $25)$; возможность получать помощь и поддержку педагогов (вопрос 4); безопасность и доверие в отношениях со сверстниками (вопросы 9, 11, 12, $23,24,26,27)$; проявления насилия в образовательной среде (буллинг, моббинг) вопросы 13, 14, 15; столкновение с насилием вне учебного заведения (вопросы 20, 21); внеучебная занятость (вопросы 16, 17, 18); семейное благополучие (вопросы 19, 22). Результаты исследования представлены в таблице 1.

Таблица 1. - Результаты анкетирования, представленные в процентном соотношении в общей выборке и группе риска

\begin{tabular}{|c|c|c|c|}
\hline \multirow{2}{*}{ № } & \multirow{2}{*}{$\begin{array}{c}\text { Вопрос анкеты } \\
(* * \text { отмечен уровень значимости различий } \mathrm{p}<0.001, \\
\text { * отмечен уровень значимости различий } \mathrm{p}<0.01)\end{array}$} & \multicolumn{2}{|c|}{$\begin{array}{l}\text { Доля положительных } \\
\text { ответов (\%) }\end{array}$} \\
\hline & & $\begin{array}{c}\text { Общая } \\
\text { выборка }\end{array}$ & $\begin{array}{l}\text { Группа } \\
\text { риска }\end{array}$ \\
\hline 1 & Обучение в школе приносит мне радость и удовлетворение & 68,8 & 13,0 \\
\hline 2 & Свое обучение в школе я считаю интересным $* *$ & 73,3 & 16,4 \\
\hline 3 & Расписание уроков дает мне возможность избежать сильного утомления** & 54,4 & 12,4 \\
\hline 4 & У меня всегда есть возможность получать поддержку и помощь педагогов** & 74,2 & 16,3 \\
\hline 5 & У меня есть возможность открыто высказывать свою позицию, точку зрения** & 75,9 & 25,0 \\
\hline 6 & $\begin{array}{l}\text { Я имею возможность отказаться от участия в школьных мероприятиях, которые } \\
\text { мне не интересны** }\end{array}$ & 76,1 & 44,7 \\
\hline 7 & Если бы мне пришлось выбирать из всех школ района, я бы выбрал свою** & 83,3 & 33,4 \\
\hline 8 & Учителя часто обвиняют ребят ни за что** & 27,2 & 73,1 \\
\hline 9 & $\begin{array}{l}\text { Если возникают личные проблемы или затруднения, я могу рассчитывать на } \\
\text { поддержку и помощь со стороны одноклассников** }\end{array}$ & 73,5 & 17.5 \\
\hline 10 & $\begin{array}{l}\text { В школе я редко испытываю отрицательные эмоции (страх, гнев, обида), } \\
\text { связанные с учебой, отношениями с учителями, одноклассниками** }\end{array}$ & 61,9 & 17,5 \\
\hline 11 & Большинству ребят в нашей школе можно доверять ** & 64,2 & 11,97 \\
\hline 12 & Ребята нашей школы скорее будут помогать друг другу, чем оскорблять друг друга** & 73,6 & 19,3 \\
\hline 13 & Ребята в школе почти никогда не дерутся** & 68,8 & 26,0 \\
\hline 14 & Я никогда не был свидетелем травли (буллинга, моббинга) учеников** & 63,1 & 19,5 \\
\hline 15 & Я никогда не подвергался травле (буллингу, моббингу) в школе** & 72,7 & 23,1 \\
\hline 16 & Я принимаю участие в деятельности молодежных организаций города и республики* & 39,9 & 16,1 \\
\hline 17 & Я посещаю внеклассные занятия и кружки в школе** & 46,1 & 17,7 \\
\hline 18 & Я посещаю занятия вне школы (спорт, техника, искусство и др.)** & 64,6 & 34,6 \\
\hline 19 & Я проживаю в полной семье** & 80,3 & 50,5 \\
\hline 20 & Я часто являюсь свидетелем насилия на улице** & 0,05 & 52,4 \\
\hline 21 & Меня часто избивают на улице** & 0,02 & 28,2 \\
\hline 22 & Я считаю, что счастлив в своей семье** & 96,4 & 40,1 \\
\hline 23 & У меня всегда есть с кем поделиться в классе радостью или проблемами** & 82,0 & 25,9 \\
\hline 24 & У меня есть верные друзья** & 90,8 & 42,2 \\
\hline 25 & $\begin{array}{l}\text { В школе я чувствую себя защищенным от необоснованной критики со стороны } \\
\text { учителей** }\end{array}$ & 69,8 & 13,02 \\
\hline 26 & Мы всегда защищаем одноклассника, которого обижают** & 86,8 & 35,6 \\
\hline 27 & $\begin{array}{l}\text { Доверять ребятам в нашем классе небезопасно, так как они могут легко } \\
\text { использовать это в своих интересах** }\end{array}$ & 33,9 & 80,0 \\
\hline
\end{tabular}

Результаты исследования показывают, что в восприятии обучающимися образовательной среды по выборке в целом и в группе респондентов с высоким суммарным баллом 
агрессивности и депрессивности по всем изученным аспектам существуют статистически значимые различия. По отдельным вопросам, связанным с насилием, защищенностью, безопасностью и возможностью получать поддержку в образовательном пространстве, показатели группы риска отличаются от выборочных значений кратно в 3 - 5 раз. Интерпретация количественных результатов исследования позволяет сделать следующие вblвoдbl.

Агрессивно-депрессивные

лица подросткового и юношеского возраста достоверно чаще своих сверстников:

- испытывают негативные эмоциональные состояния, связанные с учебой и отношениями между субъектами образовательного процесса;

- подвергаются

буллингу

B

образовательной среде;

- сталкиваются с проявлениями насилия на улице;

- сами являются жертвами насилия вне учебного заведения;

- чувствуют себя незащищенными от необоснованной критики и обвинений со стороны учителей;

- отмечают дефицит позитивных связей со сверстниками.

Агрессивно-депрессивные лица подросткового и юношеского возраста по сравнению со своими сверстниками менее склонны:

- рассчитывать на поддержку и помощь со стороны педагогов;

- доверять

одноклассникам

и

одногруппникам;

- рассчитывать на помощь и поддержку в кругу сверстников;

- открыто высказывать свою позицию и точку зрения;

- делиться с одноклассниками своими проблемами;

- с считать себя счастливыми в своей семье.

Другие, менее выраженные характеристики группы риска, - проживание в неполной семье $(49,5 \%)$, сниженная вовлеченность в компенсаторные виды активности (спорт, увлечения, искусство, дополнительные занятия и кружки), отсутствие верных друзей $(57,8 \%)-$ дополняют картину неблагополучия этих ребят.

В общении и взаимодействии с лицами подросткового и юношеского возраста, для которых характерна агрессивно-депрессивная симптоматика, необходимо учитывать многие переменные. В первую очередь - исходить из факта, что картина мира этой категории молодых людей кардинально отличается от картины мира их «среднестатистических» сверстников в сторону большей незащищенности, небезопасности, недоверия и одиночества. В силу этих особенностей данная категория лиц особенно чувствительна и уязвима к действию неблагоприятных факторов, которыми пестрят будни школьника или студента: постоянное психическое напряжение, вызванное оценочными отношениями, угрозы самоуважению и самооценке, настороженность и страх по поводу небезопасности, непредсказуемая вероятность унижения и связанные с ним стыд и страх стыда, общий негативный эмоциональный фон, опасения по поводу несоответствия ожиданиям родителей, установление новых межличностных отношений. Подобная уязвимость многократно усиливается семейным неблагополучием и дефицитарностью компенсаций вне образовательной организации. Если подобные условия имеют постоянный режим воздействия, то складывается хроническая ситуация бессилия, беспомощности, безысходности и невозможности повлиять на обстоятельства. Таким образом, внутренний, интрапсихический фон приобретает все признаки психологической травмы.

Основная идея, которая должна быть услышана в итоге проведенного исследования, такова. Дети, подростки и молодые люди, чье психическое состояние характеризуется сочетанием высокой агрессивности и высокой депрессивности, воспринимают образовательную среду как довольно враждебную, а отношения с педагогами и сверстниками как небезопасные. Данную картину мира ни в коем случае нельзя считать искаженной и / или ложной, поскольку ее носители действительно сталкивались в своем опыте с фактами насилия, социального остракизма, несправедливости, незащищенности, отсутствия поддержки и помощи со стороны взрослых фигур и невозможностью полагаться даже на друзей. Говорить о том, что их более благополучные сверстники правы, а они - нет, бессмысленно и даже опасно. В области немедицинской психотерапии данные обстоятельства - бессилия, беспомощности и наличия перманентных угроз - характеризуются как травмоопасные, и личность, уязвимая к неблагоприятным воздействиям и ограниченная в способах совладания (копингах), имеет все шансы с ними не справиться. Неизбежными следствиями этого будут отклонения в сфере психического и соматического здоровья, суицидальные риски и многочисленные вариации девиантного поведения. 
Заключение. Качественный анализ анкетирования позволил выделить и описать внутренние репрезентации различных характеристик образовательной среды в сознании обучающихся. В ходе количественного анализа выявлены специфические особенности в восприятии образовательной среды лицами с высоким суммарным уровнем агрессивности и депрессивности.

Новизна исследования состоит в том, что на репрезентативной выборке показано, насколько сильно в группе риска агрессивно-депрессивного спектра отношение к образовательной среде смещено в сторону недоверия, небезопасности, незащищенности, бессилия и беспомощности.

Аналитические выводы, полученные в результате исследования, адресованы лицам, способным повлиять на изученные факторы в сторону улучшения образовательного пространства учебных заведений: в первую очередь государственным служащим и представителям администрации образовательных организаций; сотрудникам правоохранительных органов, причастным к работе с детьми и молодежью; школьным учителям и классным руководителям; преподавателям колледжей и вузов; психологам, чья профессиональная деятельность протекает в системах образования, здравоохранения и социальной защиты.

Материалы исследования могут быть использованы в решении задач психологической профилактики отклоняющегося поведения детей и молодежи, улучшения психологического климата учебных заведений, сопровождения процессов адаптации школьников и студентов в кризисные периоды. В целом, закономерности и выводы, представленные в данной статье, позволят объединить усилия разных специалистов, направленные на создание саногенной образовательной среды, учитывающей новые факторы риска и требования современной психогигиены. Результаты проведенного исследования могут быть применимы в нескольких направлениях: психологическое просвещение всех субъектов образовательного процесса, профилактика психических расстройств агрессивнодепрессивного спектра, психогигиена образовательной среды, психологическое сопровождение обучающихся группы риска и превенция отклоняющегося поведения антисоциальной направленности.

Лаборатория изучения отклоняющегося поведения Института педагогики, психологии и социальных проблем выражает огромную благодарность сотрудникам Ресурсного центра координации деятельности психологических служб «Ориентир» ГБУ «Республиканский центр молодежных, инновационных и профилактических программ», занятых в организации и проведении мониторинга и предоставившим на основании договора о сотрудничестве возможность анализа данных директору Ресурсного центра Хакимзянову Р.Н., руководителю отдела мониторинга Самаркину О.А., методисту отдела мониторинга Королёвой Н.А., сотрудникам Ибрагимовой А.И., Гармоновой А.А.

\section{Лumepamypa:}

1. Андронникова О.О. Безопасность образовательной среды как условие сохранения физического и психологического здоровья участников образовательного процесса / О.О. Андронникова // СМАЛЬТА. - 2019. - № 1. - С. 5-14.

2. Баева И.А. Психологическая безопасность в образовании: монография / И.А. Баева. - СПб. - 2002. $271 \mathrm{c}$.

3. Баева И.А., Лактионова Е.Б. Модель психологической безопасности подростка в образовательной среде / И.А. Баева, Е.Б. Лактионова, Л.А. Гаязова, И.В. Кондакова // Известия РГПУ им. А.И. Герцена. - 2019. - № 194. - С. 7-18.

4. Баева И.А., Кондакова И.В. Психологическая безопасность образовательной среды в оценках педагогов и учащихся колледжей: сборник / И.А. Баева, И.В. Кондакова // Профилактика девиантного поведения детей и молодежи: региональные модели и технологии / Материалы Второй Международной научно-практической конференции (8-10 октября 2020 года); под научной ред. В.В. Коврова. - Симферополь: ИТ «АРИАЛ», 2020. - С. 213-221.
5. Бекоева М.И. Безопасная образовательная среда как фактор успешной познавательной деятельности студентов / М.И. Бекоева // Балтийский гуманитарный журнал. - 2017. - Т. 6. - № 4(21). - С. 259-261.

6. Бойкина Е.Э. Агрессия сквозь призму социального остракизма / Е.Э. Бойкина // Электронный журнал «Современная зарубежная психология». 2019. - T. 8. - № 3. - С. 60-67.

7. Зинченко Ю.П. Методологические основы психологии безопасности / Ю.П. Зинченко // Национальный психологический журнал. - 2011. - № 2(6). - C. 11-14.

8. Карпова Э.Б., Исурина Г.Л., Журавлев А.Л. Психологическая концепция отношений В.H. Мясищева: основы и содержание / Э.Б. Карпова, Г.Л. Исурина, А.Л. Журавлев // Психологический журнал. 2020. - T. 41. - № 2. - С. 5-14.

9. Козлова О.В. Психология безопасности образовательной среды в некоторых зарубежных исследованиях начала XXI века / О.В. Козлова // 
Современная зарубежная психология. - 2012. - № 3. C. $62-70$.

10. Личко А.Е. Психопатии и акцентуации характера у подростков / А.Е. Личко. - СПб.: Питер. 2019. - 304 c.

11. Мясищев В.Н. Личность и неврозы / В.Н. Мясищев. - Ленинград: Изд-во Ленингр. ун-та. - 1960. $-426 \mathrm{c}$

12. Мясищев В.Н. Психология отношений / В.Н. Мясищев. - М.: МПСИ. - 2005. - 158 с.

13. Федунина Н.Ю. Психологический климат в школе: к вопросу о структуре понятия / Н.Ю. Федунина // Современная зарубежная психология.2014. - № 1. - C. 117-124.
14. Эгамбердиева Е.В. Социальнопсихологический климат студенческих групп и психологическая безопасность образовательной среды вуза / Е.В. Эгамбердиева // Институт психологии Российской академии наук. Социальная и экономическая психология. - 2018. - Т. 3. - № 3(11). C. 130-161.

15. Briere F.N., Pascal S., Dupere V., Janosz M. School Environment and Adolescent Depressive Symptoms: A Multilevel Longitudinal Study // Pediatrics. 2013. - № 131(3). - pp. 702-708.

16. Williams K.D. Ostracism: a temporal need-threat model. In Zanna M. (ed.) // Advances in Experimental Social Psychology. - 2009. - vol. 41. - pp. 279-314.

\section{References:}

1. Andronnikova OO Safety of the educational environment as a condition for the preservation of physical and psychological health of participants in the educational process / O.O. Andronnikov // SMALTA. - 2019. - № 1. S. 5-14.

2. Baeva I.A. Psychological safety in education: monograph / I.A. Baeva. - SPb. - 2002. - 271 p.

3. Baeva I.A., Laktionova E.B. Model of psychological safety of a teenager in an educational environment / I.A. Baeva, E.B. Laktionova, L.A. Gayazova, I.V. Kondakov // Izvestia RSPU im. A.I. Herzen. - 2019. - № 194. - S. 7-18.

4. Baeva I.A., Kondakova I.V. Psychological safety of the educational environment in the assessments of teachers and students of colleges: collection / I.A. Baeva, I.V. Kondakova // Prevention of deviant behavior in children and youth: regional models and technologies / Materials of the Second International Scientific and Practical Conference (October 8-10, 2020); under the scientific ed. V.V. Kovrov. - Simferopol: IT "ARIAL", 2020. - S. 213-221.

5. Bekoeva M.I. Safe educational environment as a factor of successful cognitive activity of students / M.I. Bekoeva // Baltic Humanitarian Journal. - 2017. - T. 6. - № 4(21). - S. 259-261.

6. Boykina E.E. Aggression through the prism of social ostracism / E.E. Boykina // Electronic journal "Contemporary Foreign Psychology". - 2019. - T. 8. - № 3. - S. 60-67.

7. Zinchenko Yu.P. Methodological foundations of safety psychology / Yu.P. Zinchenko // National psychological journal. - 2011. - № 2(6). - S. 11-14.

8. Karpova E.B., Isurina G.L., Zhuravlev A.L. The psychological concept of relations by V.N. Myasishcheva: basics and content / E.B. Karpova, G.L. Isurina, A.L. Zhuravlev // Psychological journal. - 2020. - T. 41. - № 2. S. 5-14.

9. Kozlova O.V. Psychology of the safety of the educational environment in some foreign studies at the beginning of the XXI century / O.V. Kozlova // Modern foreign psychology. - 2012. - № 3. - S. 62-70.

10. Lichko A.E. Psychopathies and character accentuations in adolescents / A.E. Lichko. - SPb.: Peter. 2019. - 304 p.

11. Myasishchev V.N. Personality and neuroses / V.N. Myasishchev. - Leningrad: Publishing house Leningrad. un-that. - 1960. - 426 p.

12. Myasishchev V.N. Psychology of relations / V.N. Myasishchev. - M.: MPSI. - 2005. - 158 p.

13. Fedunina N.Yu. Psychological climate at school: on the question of the structure of the concept / N.Yu. Fedunina // Modern foreign psychology. - 2014. - № 1. - P. 117-124.

14. Egamberdieva E.V. Socio-psychological climate of student groups and psychological safety of the educational environment of the university / E.V. Egamberdieva // Institute of Psychology of the Russian Academy of Sciences. Social and economic psychology. 2018. - T. 3. - № 3(11). - S. 130-161.

15. Briere F.N., Pascal S., Dupere V., Janosz M. School Environment and Adolescent Depressive Symptoms: A Multilevel Longitudinal Study // Pediatrics. 2013. - No. 131 (3). - pp. 702-708.

16. Williams K.D. Ostracism: a temporal need-threat model. In Zanna M. (ed.) // Advances in Experimental Social Psychology. - 2009. - vol. 41. - pp. 279-314.

19.00.07 - Педагогическая психология

\section{Сведения об авторе:}

Ничипоренко Надежда Павловна (г. Казань, Россия), кандидат психологических наук, доцент, старший научный сотрудник, заведующая лабораторией изучения отклоняющегося поведения ФГБНУ «ИППСП», методист отдела сопровождения психологической деятельности, супервизор Ресурсного центра координации деятельности психологических служб «Ориентир» ГБУ «Республиканский центр молодежных, инновационных и профилактических программ», e-mail nichiporenko.n@yandex.ru 